\title{
Can a Mendelian Randomization Study Predict the Results of a Clinical Trial? Yes and No
}

\author{
Antonio Abbate ${ }^{1}$, Charles A. Dinarello ${ }^{2}$, Mariangela Peruzzi ${ }^{3}$, Sebastiano Sciarretta ${ }^{3,4}$, \\ Giacomo Frati ${ }^{3,4}$ and Giuseppe Biondi-Zoccai ${ }^{3,5},{ }^{*}$ \\ ${ }^{1}$ VCU Pauley Heart Center, Virginia Commonwealth University, Richmond, VA, USA \\ ${ }^{2}$ Division of Infectious Diseases, Department of Medicine, University of Colorado, Denver, CO, USA \\ ${ }^{3}$ Department of Medico-Surgical Sciences and Biotechnologies, Sapienza University of Rome, Latina, Italy \\ ${ }^{4}$ Department of AngioCardioNeurology, IRCCS Neuromed, Pozzilli, Italy \\ ${ }^{5}$ Eleonora Lorillard Spencer Cenci Foundation, Rome, Italy
}

\begin{abstract}
Randomized controlled trials are considered at the top of the evidence hierarchy. However, in several cases randomized trials cannot be conducted or have not yet been completed. In such settings observational studies may provide important inference, yet traditional statistical adjustment methods fall short of controlling for all potential confounders, as unknown confounders cannot be taken care of by even the most sophisticated statistical tools. The mendelian randomization study is a type of research design which simultaneously exploits random transmission of genes and genetic linkage to obtain inferential estimates from the association between specific genetic variants known to modulate given risk factors and the corresponding outcomes of interests. Despite several developments in this field, there remain several areas of further research, and discrepancies between mendelian randomization studies and the corresponding randomized trials have already been recognized. Nonetheless, it is likely that this novel type of study will be used more commonly in the future, and a working knowledge of its pros, cons, and range of validity is crucial for conscientious interpretation and application. We thus aimed to concisely yet poignantly introduce the scholarly reader to this novel type of research design, notwithstanding that complementarity prevails in most cases over overlap between mendelian randomization studies and randomized trials.
\end{abstract}

Keywords: Adjustment, Confounding, Inference, Mendelian randomization study, Observational study, Prediction, Randomized controlled trial.

\section{INTRODUCTION}

Clinical decision-making should best be based on formal scientific experiments. It is widely accepted that a large randomized trial represents the best single piece of clinical evidence, whereas a homogeneous pairwise meta-analysis is considered the best comprehensive source of scholarly information [1-2]. Yet, novel developments in clinical research methods, which are posed to challenge the role of randomized controlled trials and pairwise meta-analyses, are being steadfastly developed, and include mendelian randomization studies, network meta-analyses, and umbrella reviews [3-5]. Whilst network meta-analyses and umbrella reviews typically incorporate one or more randomized trials, thus borrowing their strengths [6], the mendelian randomization approach has been proposed in as early as 1991 to minimize confounding in observational studies [7].

The preamble is of course that it remains impossible to conduct in a timely and ethical fashion a randomized

*Address correspondence to this author at the Department of Medico-Surgical Sciences and Biotechnologies, Sapienza University of Rome, Corso della Repubblica 79, 04100, Latina, Italy; Tel: +39 0773 1757245; Fax: +390773 1757254; E-mail: giuseppe.biondizoccai@uniroma1.it trial for any given topic of interest [8-9]. Accordingly, observational studies (either explicitly designed or retrospectively analyzed) remain an important source of evidence, albeit of lesser strength. Indeed, observational studies are always fraught with a risk of residual confounding by unknown or inappropriately adjusted effect modifiers [10]. From stratification to logistic regression and propensity score matching, traditional adjustment methods have become more and more refined, and in many cases carefully conducted and analyzed observational studies appear to agree with the corresponding megatrials [11]. Yet, several examples of observational inference later disproved by a randomized trial are available.

\section{THE MENDELIAN RANDOMIZATION STUDY}

In order to overcome the limitations of traditional adjustment methods, and exploit the unique features of genetics, Gray and Wheatley proposed the mendelian randomization study (Figure 1) [7,12]. This type of research aims to adjust for known and unknown confounders when aiming at observational inference, exploiting Mendel second law of inheritance, which specifies that separate genes are inherited independently from each other, as long as they reside 


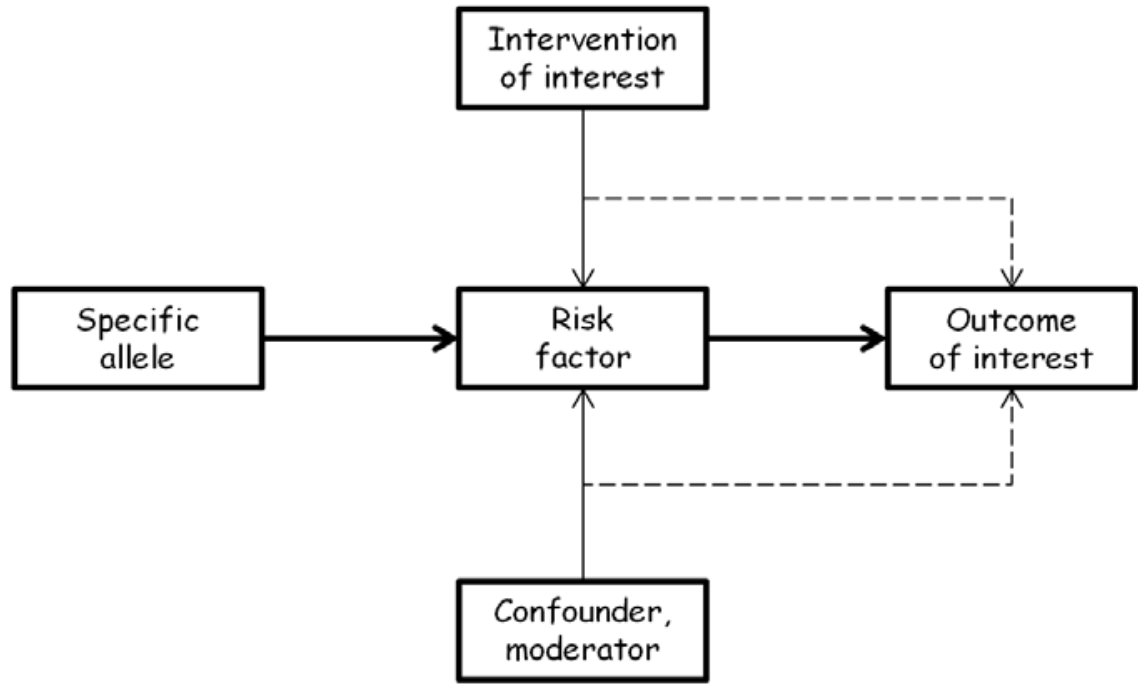

Figure 1: Interactions between genetics, confounders, interventions, risk factors, and outcomes. Schematic representation of the logical flow from specific alleles to risk factor modulation and outcomes in a mendelian randomization study (thick arrows). An observational study relies on traditional statistical adjustment, which takes into account the impact on risk factors of known confounders and moderators but cannot adjust for the impact on outcomes of unknown confounders (thin and dashed lines, respectively). A randomized controlled trial focuses on a specific intervention of interest and formally tests its impact on a given risk factor or, more importantly, on an outcome of interest (thin and dashed lines, respectively), and asymptotically balances the distribution of known and unknown confounders.

on separate chromosomes. It basically relies on one or more alleles known to be associated with a risk factor of interest. Once such genetic association is proved beyond random variability, then the association between such genetic variants and the outcomes of interest is explored. As genetic variants are assumed to be randomly assigned at conception, the association between such genetic variants and a given condition can be considered independent of confounders. This is quite different from observational studies and randomized trials. Specifically, an observational study relies on traditional statistical adjustment, which takes into account the impact on risk factors of known confounders and moderators but cannot adjust for unknown confounders. A randomized trial focuses on a specific intervention of interest and formally tests its impact on a given risk factor or, more importantly, on an outcome of interest, and asymptotically balances the distribution of known and unknown confounders.

Several authors have welcomed this innovative tool which builds on the expanding knowledge base on genetics as a means to test novel hypotheses or retest apparently established ones, given the assumed superiority to traditional statistical adjustment tools [7,12-13]. There remain some theoretical caveats, though. First, a prerequisite of any mendelian randomization study is a reliable association between genotype and exposure and a clear understanding of the pathophysiology of the genetic variants of interest.
This can be taken for granted in many cases, but more robust proof may remain elusive in some cases. Second, confounding may still occur due to linkage disequilibrium. Third, genetic variants with multiple effects may confound the results. Fourth, canalization, which can be defined as the modulation of the effects of genetic variations during development, may also significantly impact on the association between genotype and outcomes. Accordingly, the real virtue of mendelian randomization studies for causal inference rather than association appraisal remains debated, and it is not unexpected that mendelian randomization studies still represent only a paucity of observational studies. Indeed, a dedicated PubMed search (updated on July 28,2015$)$ for '(mendelian AND random*)', and restricted to works published within the prior 5 years, highlighted 541 citations, which pale in comparison to the 89,911 for '(logistic AND regression)', the 11,639 for 'cox AND hazard AND analysis', and the 6,912 for 'propensity AND (score* OR match*)', representing, respectively, citations of studies reporting on logistic regression, Cox proportional hazard analysis, and propensity score adjustment/matching.

\section{CASE STUDIES}

Under the premise of aiming at a simplified take at mendelian randomization studies, we may elaborate that two typical examples of such studies can be found in the scholarly literature. The first is a study exploiting 
specific genetic variants and which does not relate to any given clinical intervention yet. Accordingly, it cannot be directly compared to prior, current or future randomized controlled trials. For instance, the mendelian randomization study with the largest number of scholarly citations in Google Scholar is an observational study using both traditional statistical adjustment techniques and mendelian randomization to appraise the association between C-reactive protein and blood pressure/hypertension [14]. As no pharmacologic intervention specifically and selectively targeting C-reactive protein levels or activity is yet available, the findings from this study cannot be directly confirmed or disproved, nor formally applied.

The second type of mendelian randomization analysis is instead a study which focuses on an association which can also be translated into a therapeutic intervention study, i.e. a randomized controlled trial. Perusal of a set of key applications of mendelian randomization studies in this specific fashion may inform the scholarly reader on the pros and cons of this novel analytical approach (Table 1). For instance, the impact of alcohol consumption on blood pressure has been analyzed within the context of mendelian randomization by Chen et al., with results similar to those provided in a comprehensive metaanalysis of randomized controlled trials on alcohol cessation [15-16]. Specifically, a common polymorphism in aldehyde dehydrogenase 2 , which is an established surrogate for measuring alcohol consumption, was associated with increased blood pressure and increased risk of hypertension, similarly to the established impact of alcohol intake on blood pressure and hypertension risk.

The above and other favorable cases of agreement between mendelian randomization studies and randomized controlled trials are reassuring, yet it is not easy to identify cases in which there was a substantial agreement or discrepancy between a mendelian randomization study and the corresponding randomized controlled trial. Specifically, an informal scholarly search enabled us to recognize substantial

Table 1: Comparative Analysis between Selected Mendelian Randomization Studies and Corresponding Randomized Controlled Trials or Meta-Analyses, Highlighting Key Drivers of Agreement and Discrepancy between these Two Types of Research Endeavors

\begin{tabular}{|c|c|c|c|}
\hline Association & Mendelian randomization study (MRS) & Randomized controlled trial (RCT) & Comparative analysis \\
\hline $\begin{array}{l}\text { Alcohol - blood } \\
\text { pressure }\end{array}$ & $\begin{array}{l}\text { Chen (2008): MRS with meta-analysis of } 8 \\
\text { studies of a common polymorphism in aldehyde } \\
\text { dehydrogenase } 2 \text { (ALDH2) as a surrogate for } \\
\text { measuring alcohol consumption and blood } \\
\text { pressure/hypertension, suggesting that alcohol } \\
\text { intake is significantly associated with blood } \\
\text { pressure and hypertension }\end{array}$ & $\begin{array}{l}\text { Xin (2001): meta-analysis of } 15 \text { RCTs } \\
\text { comparing the effect alcohol cessation } \\
\text { versus control on blood pressure, } \\
\text { suggesting that alcohol cessation is } \\
\text { associated with significant reductions in } \\
\text { blood pressure }\end{array}$ & $\begin{array}{l}\text { Agreement between MRS } \\
\text { and RCT, with both } \\
\text { supporting prior evidence } \\
\text { of an association from } \\
\text { traditional observational } \\
\text { studies }\end{array}$ \\
\hline $\begin{array}{c}\text { B-type } \\
\text { natriuretic } \\
\text { peptide (BNP)- } \\
\text { diabetes }\end{array}$ & $\begin{array}{l}\text { Pfister (2011): MRS with meta-analysis of } 11 \\
\text { case-control studies of the variant rs } 198389 \\
\text { within the BNP locus and the incidence of type } \\
2 \text { diabetes, suggesting a significant association } \\
\text { between BNP and diabetes }\end{array}$ & $\begin{array}{l}\text { Yancy (2004): RCT in } 210 \text { patients with } \\
\text { heart failure receiving nesiritide } \\
\text { (recombinant form of the } 32 \text { amino acid } \\
\text { human BNP) versus placebo, suggesting } \\
\text { no significant impact of nesiritide on } \\
\text { glucose tolerance }\end{array}$ & $\begin{array}{l}\text { Discrepancy between MRS } \\
\text { and RCT, with the latter not } \\
\text { confirming the MRS results }\end{array}$ \\
\hline $\begin{array}{l}\text { Vitamin D - } \\
\text { blood lipid } \\
\text { profile }\end{array}$ & $\begin{array}{c}\text { Skaaby (2013): MRS combining } 3 \text { studies and } \\
\text { including 12,911 subjects of } 3 \text { filaggrin gene } \\
\text { mutations (R501X, 2282del4, and R2447X) and } \\
\text { blood lipid profile, suggesting a significant } \\
\text { association between the mutations and an } \\
\text { adverse lipid profile }\end{array}$ & $\begin{array}{c}\text { Pilz (2015): RCT in } 200 \text { subjects of } \\
\text { vitamin D3 versus placebo, suggesting } \\
\text { no significant impact of vitamin D3 on } \\
\text { blood lipid profile }\end{array}$ & $\begin{array}{l}\text { Discrepancy between MRS } \\
\text { and RCT, with latter not } \\
\text { confirming the MRS results }\end{array}$ \\
\hline $\begin{array}{l}\text { Vitamin D - } \\
\text { mortality }\end{array}$ & $\begin{array}{l}\text { Trummer (2013): MRS including } 3316 \text { subjects } \\
\text { of } 3 \text { common single-nucleotide polymorphisms } \\
\text { (SNPs) associated with 25-OH-vitamin D } \\
\text { concentrations and mortality, suggesting no } \\
\text { significant association between them }\end{array}$ & $\begin{array}{l}\text { Chowdhury (2014): meta-analysis of } 22 \\
\text { RCTs on vitamin D2 and D3 } \\
\text { supplementation, suggesting that only } \\
\text { vitamin D3 is associated with a } \\
\text { significantly reduced risk of mortality }\end{array}$ & $\begin{array}{l}\text { Discrepancy between MRS } \\
\text { and RCT, with latter } \\
\text { suggesting a mortality } \\
\text { benefit apparently } \\
\text { disproved by the MRS } \\
\text { results }\end{array}$ \\
\hline $\begin{array}{l}\text { Testosterone- } \\
\text { Cardiovascular } \\
\text { risk }\end{array}$ & $\begin{array}{c}\text { Haring (2013): MRS in } 1882 \text { men of } \\
\text { polymorphisms at the SHBG gene } \\
\text { (rs12150660) and X chromosome (rs5934505) } \\
\text { and cardiovascular risk }\end{array}$ & $\begin{array}{c}\text { Corona (2014): meta-analysis of } 75 \\
\text { RCTs on testosterone-boosting } \\
\text { medications, suggesting no significant } \\
\text { impact of these drugs on cardiovascular } \\
\text { risk }\end{array}$ & $\begin{array}{l}\text { Agreement between MRS } \\
\text { and RCT, with both not } \\
\text { supporting prior evidence } \\
\text { of an association from } \\
\text { traditional observational } \\
\text { studies }\end{array}$ \\
\hline
\end{tabular}


discrepancies only in pairs of studies appraising the impact on B-type natriuretic peptide on diabetes, and of vitamin $\mathrm{D}$ on blood lipid profile and mortality [17-22].

Another recent and interesting case study in mendelian randomization analysis is the one focusing on interleukin-1 receptor antagonist (IL-1Ra), and its association with the risk of adverse blood lipid profile, coronary heart disease, stroke, and aortic aneurysm [23]. Notwithstanding the general limitations of mendelian randomization [24], in this specific study the use of the term 'cardiovascular risk' was potentially misleading, as risk implies the likelihood of an event occurring over time, and therefore one would need to explore the incidence of an event, rather than the prevalence. In addition, the value of this type analysis inevitably depends on the quality of the original studies, and therefore it cannot be free of enrollment or survivor biases deriving from the original studies. In addition, its findings are not clearly consistent with prior genetic association data exploring the impact of IL-1, IL-1Ra and the effects of proven cardioprotective agents such as HMG-CoA inhibitors, such as those reported Waehre et al. [25].

More specifically, let us consider a hypothetical scenario by which gene $X$ modulates the 'risk' of dying from disease $A$, by which carriers of $X$ are more likely to have a more severe form of $A$, by which when they become ill, they develop more complications, and die sooner. If we were to perform a cross-sectional study of all subjects with the disease $A$, we could paradoxically find that less subjects carrying $X$ with the disease $A$ will be represented because $X$-carriers have a shorter duration of the disease $\mathrm{A}$ before severe complications or death occur. In this specific case, the authors found that carriers of hyper-producing IL-1Ra gene alleles have mildly higher levels of IL-1Ra and mildly lower levels of C-reactive protein, yet mildly higher levels of low-density lipoprotein cholesterol. The authors suggested that IL-1Ra is increasing low-density lipoprotein cholesterol (LDL), which is known to associate with coronary artery disease, and hence have IL-1Ra enhancing the likelihood of coronary artery disease through increased LDL (Figure 2). Yet, what if it were not the case, and, on the other hand, higher IL1 Ra levels were reducing mortality/increasing longevity in patients with coronary artery disease [26], a way by which IL-1Ra would be modulating the negative effects of LDL? This example, while interesting and potentially informative, is however based on several untested and non-evidence-based assumptions.

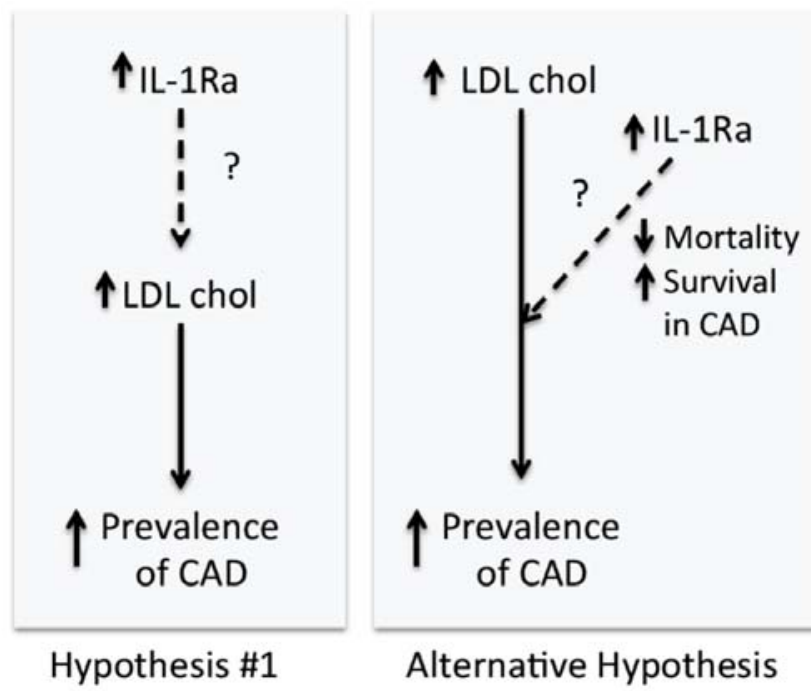

Figure 2: Case mendelian randomization studiy. In a recent mendelian randomization study exploring the association between interleukin-1 (IL-1) receptor antagonist (IL-1Ra) genotypes with higher IL-1Ra plasma levels and higher prevalence of coronary artery disease, the authors suggested that IL-1Ra causes coronary artery disease, possibly through increased levels of low-density lipoprotein (LDL) cholesterol. While this is biologically possible it is not evidently plausible as there are no biologic data linking IL$1 \mathrm{Ra}$ to increased LDL levels nor to increased prevalence of coronary artery disease. An alternative hypothesis would be that higher IL-1Ra levels may affect the prevalence of coronary artery disease by increasing survival so that the actual prevalence of this condition is increased. This hypothesis is possible and also plausible, as there are preclinical and clinical data linking enhanced IL-1 activity and worse outcomes in coronary artery disease.

Accordingly, only time and the cumulative evidence provided by recent and ongoing randomized controlled trials on this topic will provide a definite answer to this research question [27-30], and similar considerations may apply to other mendelian randomization studies.

\section{CONCLUSIONS}

Despite their inherent limitations, the success and impact of mendelian randomization studies will likely continue to increase over time. Concomitantly, comparative research on their accuracy and precision in comparison to other types of observational research and pertinent randomized controlled trials will accrue. These efforts will further bolster the comprehensiveness of the many different layers of clinical research tools (Figure 3), under the key premise that complementarity will most often prevail over overlap between mendelian randomization studies, randomized trials and other types of research tools [31]. 


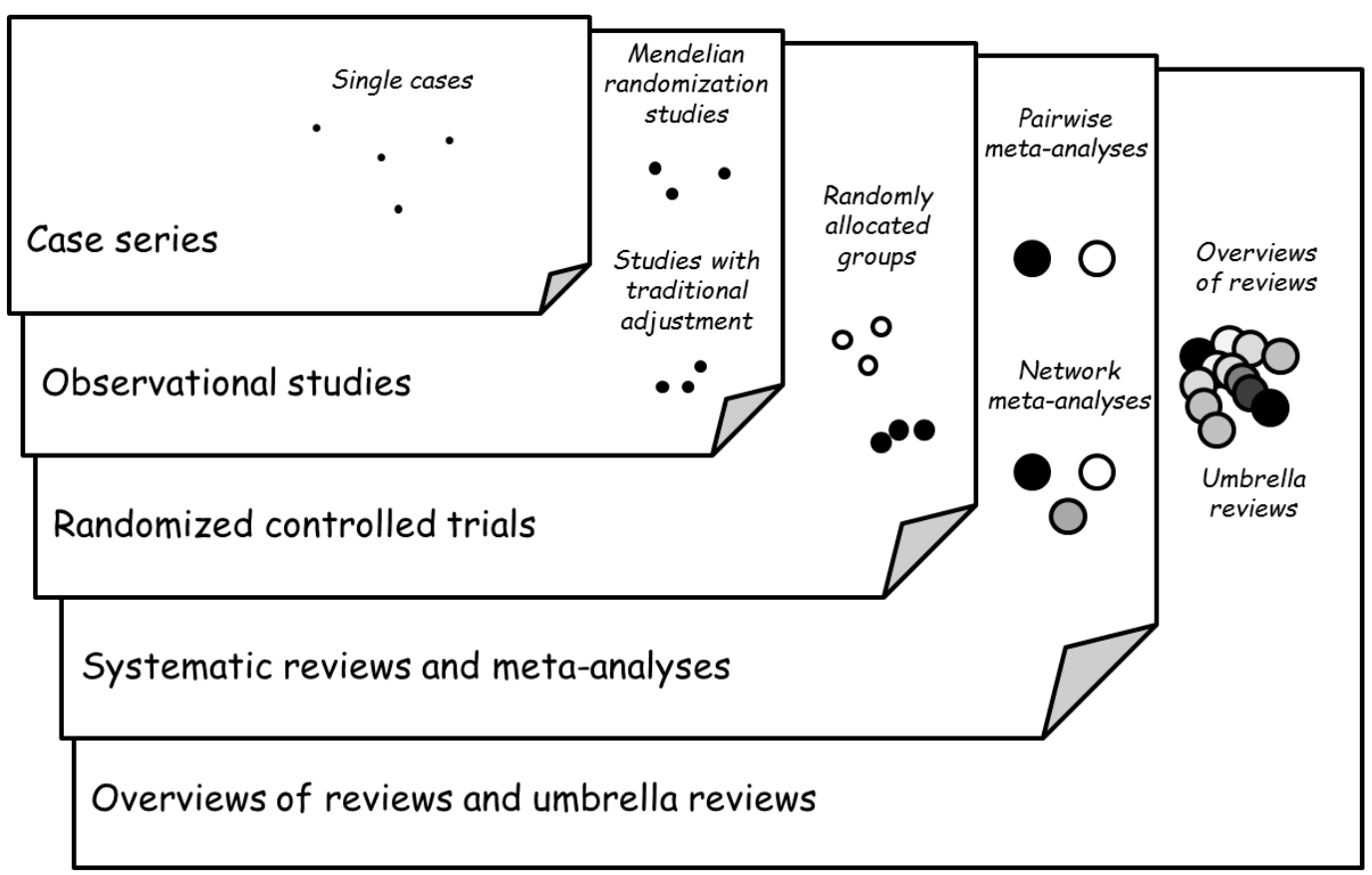

Figure 3: Schematic representation of the layers of clinical evidence, moving from cases, to case series, observational studies with traditional adjustment, mendelian randomization studies, randomized controlled trials, systematic reviews, meta-analyses, overviews of reviews and umbrella reviews.

\section{CONFLICTS OF INTEREST}

Drs. Abbate and Dinarello hold a patent entitled 'Compositions and methods for modulating cardiac conditions' (US 20130195859 A1).

\section{REFERENCES}

[1] Biondi-Zoccai, G. In the kingdom of the blind, the one-eyed man is king: the case for the International Journal of Statistics in Medical Research. Int J Stats Med Res 2013; 2: i-iv.

[2] Biondi-Zoccai, G, Lotrionte, M, Landoni, G, Modena, MG. The rough guide to systematic reviews and meta-analyses. HSR Proc Intensive Care Cardiovasc Anesth 2011; 3: 161173.

[3] Biondi-Zoccai, G, Ed. Network Meta-Analysis: Evidence Synthesis with Mixed Treatment Comparison. Hauppauge, NY: Nova Science Publishers; 2014.

[4] Biondi-Zoccai, G, Abbate, A, Peruzzi, M, Frati, G. Commentary: observations, trials, and meta-analyses: the life cycle of evidence-based endovascular therapy. J Endovasc Ther 2014; 21: 693-696. http://dx.doi.org/10.1583/14-4713C.1

[5] Jansen, H, Samani, NJ, Schunkert, H. Mendelian randomization studies in coronary artery disease. Eur Heart $\mathrm{J}$ 2014; 35: 1917-1924.

http://dx.doi.org/10.1093/eurheartj/ehu208

[6] Greco, T, Biondi-Zoccai, G, Saleh, O, et al. The attractiveness of network meta-analysis: a comprehensive systematic and narrative review. Heart Lung Vessel 2015; 7: 133-142.

[7] Gray, R, Wheatley, K. How to avoid bias when comparing bone marrow transplantation with chemotherapy. Bone Marrow Transplant 1991; 7 Suppl 3: 9-12.

[8] Smith, GC, Pell, JP. Parachute use to prevent death and major trauma related to gravitational challenge: systematic review of randomised controlled trials. BMJ 2003; 327: 14591461.

http://dx.doi.org/10.1136/bmj.327.7429.1459

[9] Lanini, S, Zumla, A, loannidis, JP, et al. Are adaptive randomised trials or non-randomised studies the best way to address the Ebola outbreak in west Africa? Lancet Infect Dis 2015; 15: 738-745.

http://dx.doi.org/10.1016/S1473-3099(15)70106-4

[10] Biondi-Zoccai, G, Romagnoli, E, Agostoni, P, et al. Are propensity scores really superior to standard multivariable analysis? Contemp Clin Trials 2011; 32: 731-740. http://dx.doi.org/10.1016/j.cct.2011.05.006

[11] Dahabreh, IJ, Sheldrick, RC, Paulus, JK, et al. Do observational studies using propensity score methods agree with randomized trials? A systematic comparison of studies on acute coronary syndromes. Eur Heart J 2012; 33: 18931901. http://dx.doi.org/10.1093/eurheartj/ehs114

[12] Burgess, S, Timpson, NJ, Ebrahim, S, Davey Smith, G Mendelian randomization: where are we now and where are we going? Int J Epidemiol 2015; 44: 379-388.

http://dx.doi.org/10.1093/ije/dyv108

[13] Bowden, J, Davey Smith, G, Burgess, S. Mendelian randomization with invalid instruments: effect estimation and bias detection through Egger regression. Int $\mathrm{J}$ Epidemiol 2015; 44: 512-25. http://dx.doi.org/10.1093/ije/dyv080

[14] Davey Smith, G, Lawlor, DA, Harbord, R, et al. Association of C-reactive protein with blood pressure and hypertension: life course confounding and mendelian randomization tests of causality. Arterioscler Thromb Vasc Biol 2005; 25: 10511056.

http://dx.doi.org/10.1161/01.ATV.0000160351.95181.d0

[15] Chen, L, Smith, GD, Harbord, RM, Lewis, SJ. Alcohol intake and blood pressure: a systematic review implementing a Mendelian randomization approach. PLoS Med 2008; 5: e52. http://dx.doi.org/10.1371/journal.pmed.0050052

[16] Xin, X, He J, Frontini, MG, Ogden, LG, Motsamai, OI, Whelton, PK. Effects of alcohol reduction on blood pressure: 
a meta-analysis of randomized controlled trials. Hypertension 2001; 38: 1112-1117. http://dx.doi.org/10.1161/hy1101.093424

[17] Pfister, R, Sharp, S, Luben, R, et al. Mendelian randomization study of B-type natriuretic peptide and type 2 diabetes: evidence of causal association from population studies. PLoS Med 2011; 8: e1001112. http://dx.doi.org/10.1371/journal.pmed.1001112

[18] Yancy, CW, Saltzberg, MT, Berkowitz, RL, et al. Safety and feasibility of using serial infusions of nesiritide for heart failure in an outpatient setting (from the FUSION I trial). Am J Cardiol 2004; 94: 595-601. http://dx.doi.org/10.1016/i.amjcard.2004.05.022

[19] Skaaby, T, Husemoen, LL, Martinussen, T, et al. Vitamin D status, filaggrin genotype, and cardiovascular risk factors: a Mendelian randomization approach. PLoS One 2013; 8: e57647. http://dx.doi.org/10.1371/journal.pone.0057647

[20] Pilz, S, Gaksch, M, Kienreich, K, et al. Effects of vitamin D on blood pressure and cardiovascular risk factors: a randomized controlled trial. Hypertension 2015; 65: 1195-1201. http://dx.doi.org/10.1161/HYPERTENSIONAHA.115.05319

[21] Trummer, O, Pilz, S, Hoffmann, MM, et al. Vitamin D and mortality: a Mendelian randomization study. Clin Chem 2013; 59: 793-797.

http://dx.doi.org/10.1373/clinchem.2012.193185

[22] Chowdhury, R, Kunutsor, S, Vitezova, A, et al. Vitamin D and risk of cause specific death: systematic review and metaanalysis of observational cohort and randomised intervention studies. BMJ 2014; 348: g1903. http://dx.doi.org/10.1136/bmj.g1903

[23] The Interleukin-1 Genetics Consortium. Cardiometabolic effects of genetic upregulation of the interleukin 1 receptor antagonist: a Mendelian randomization analysis. Lancet Diabetes Endocrinol 2015; 3: 243-253. http://dx.doi.org/10.1016/S2213-8587(15)00034-0

[24] Nitsch, D, Molokhia, M, Smeeth, L, DeStavola, BL, Whittaker, JC, Leon, DA. Limits to causal inference based on Mendelian randomization: a comparison with randomized controlled trials. Am J Epidemiol 2006; 163: 397-403.

http://dx.doi.org/10.1093/aje/kwj062

[25] Waehre, T, Yndestad, A, Smith, C, et al. Increased expression of interleukin-1 in coronary artery disease with downregulatory effects of HMG-CoA reductase inhibitors. Circulation 2004; 109: 1966-1672. Epub 2004 Mar 29.

[26] Van Tassell, BW, Toldo, S, Mezzaroma, E, Abbate, A. Targeting interleukin-1 in heart disease. Circulation 2013; 128: $1910-23$.

http://dx.doi.org/10.1161/CIRCULATIONAHA.113.003199

[27] Morton AC, Rothman AM, Greenwood JP, et al. The effect of interleukin-1 receptor antagonist therapy on markers of inflammation in non-ST elevation acute coronary syndromes: the MRC-ILA Heart Study. Eur Heart J 2015; 36: 377-84. http://dx.doi.org/10.1093/eurheartj/ehu272

[28] Abbate A, Kontos MC, Grizzard JD, et al. VCU-ART Investigators. Interleukin-1 blockade with anakinra to prevent adverse cardiac remodeling after acute myocardial infarction (Virginia Commonwealth University Anakinra Remodeling Trial [VCU-ART] Pilot study). Am J Cardiol 2010; 105: 13711377.

http://dx.doi.org/10.1016/j.amjcard.2009.12.059

[29] Abbate, A, Van Tassell, BW, Biondi-Zoccai, G, et al. Effects of interleukin-1 blockade with anakinra on adverse cardiac remodeling and heart failure after acute myocardial infarction [from the Virginia Commonwealth University-Anakinra Remodeling Trial (2) (VCU-ART2) pilot study]. Am J Cardiol 2013; 111: 1394-1400. http://dx.doi.org/10.1016/j.amjcard.2013.01.287

[30] Ridker, PM, Thuren, T, Zalewski, A, Libby, P. Interleukin-1 $\beta$ inhibition and the prevention of recurrent cardiovascular events: rationale and design of the Canakinumab Antiinflammatory Thrombosis Outcomes Study (CANTOS). Am Heart J 2011; 162: 597-605. http://dx.doi.org/10.1016/..ahj.2011.06.012

[31] Biondi-Zoccai, G, Ed. Umbrella Reviews. Evidence Synthesis with Overviews of Reviews and Meta-Epidemiologic Studies. Cham: Springer International Publishing; 2016.

(C) 2016 Abbate et al.; Licensee Lifescience Global.

This is an open access article licensed under the terms of the Creative Commons Attribution Non-Commercial License (http://creativecommons.org/licenses/by-nc/3.0/) which permits unrestricted, non-commercial use, distribution and reproduction in any medium, provided the work is properly cited. 